\title{
Best fit, best practice, or stuck in the middle? The impact of unit ownership on unit HR performance in franchise systems
}

\author{
Evelien P. M. Croonen ${ }^{1}$ • Marko Grünhagen ${ }^{2}$ • \\ Melody L. Wollan ${ }^{3}$
}

Published online: 24 April 2015

(C) The Author(s) 2015. This article is published with open access at Springerlink.com

\begin{abstract}
Franchising is an important form of entrepreneurial wealth creation in many retailing and service industries. Since Human Resource Management (HRM) is a critical factor in such industries, it is important to understand how franchisees - as semi-autonomous entrepreneurs - deal with HRM in their units and how this ultimately affects performance at the unit level. However, the very few studies linking franchisee HRM behaviors to performance have not included multi-unit franchising (MUF) as a type of unit ownership. Given the ever-increasing popularity of MUF and the unique characteristics of MUFs, this represents an important knowledge gap. We aim to fill this gap by building a theoretical framework on how the type of unit ownership affects unit HR performance within franchise systems. Building on agency, resource and entrepreneurship perspectives, we propose that units owned by single-unit franchisees (SUFs) and small MUFs (i.e., franchisees with a very small number of units) adopt a 'best fit' system regarding HRM, whereas company-owned units (COs) and units owned by larger MUFs (i.e., franchisees with a large number of units) typically adopt a 'best practice' system. Each system has its own advantages and disadvantages, which results in two contrasting propositions regarding their effects on unit performance. Moreover, we expect the units owned by medium-size MUFs to have the lowest performance since they are 'stuck in the middle' regarding their HRM system.
\end{abstract}

Evelien P. M. Croonen

e.p.m.croonen@rug.nl

Marko Grünhagen

mgrunhagen@eiu.edu

Melody L. Wollan

mlwollan@eiu.edu

1 Faculty of Economics and Business, University of Groningen, PO Box 800, 9700 AV Groningen, The Netherlands

2 School of Business, Eastern Illinois University, 3105 Lumpkin Hall, Charleston, IL 61920, USA

3 School of Business, Eastern Illinois University, 4604 Lumpkin Hall, Charleston, IL 61920, USA 
Keywords Agency Entrepreneurship · Human resource management (HRM) · Multi-unit franchising (MUF) · Resource $\cdot$ Unit performance

\section{Introduction}

Business format franchising is an increasingly important form of contractual cooperation in which franchisees pay for the right to use a franchisor's business format in running their businesses and agree to conform to the franchisor's standards (Davies et al. 2011; Gillis and Castrogiovanni 2012). Franchisees can be considered as 'semiautonomous' entrepreneurs; even though they adopt their franchisors' business formats, they take the risk of investing capital in their units' assets, they are their units' residual claimants, and they generally enjoy some decision rights (Grünhagen et al. 2013; Ketchen et al. 2011; Sorenson and Sørensen 2001).

Franchised businesses account for a large number of jobs in the US. More than 8 million people are employed in franchised establishments, which represents $7 \%$ of the total US private employment (ADP National Franchise Report November 2013 2013). However, in certain industries (e.g. retailing and services), the percentage of employment directly resulting from franchised businesses is likely to be much higher. Despite this share in the labor market, little research has been conducted into the use and effectiveness of human resource management (HRM) practices within franchise systems.

HRM is an important strategic issue in franchise systems. It has been identified in prior studies as a critical success factor in the service and retail industries (McLean 2006; Miller 2006) in which business format franchising is a widely used business model (Combs and Ketchen 2003; Welsh et al. 2006). Recent research (Brand and Croonen 2010; Castrogiovanni and Kidwell 2010; Grünhagen et al. 2013) has noted the critical contributions of HRM policies in a franchising context, both at the unit and the system level.

Franchising has been touted as a prime example of a principal-agent relationship, with the franchisor as the principal and franchisees as the agents. An agency relationship exists when one party (the principal) depends on another party (the agent) to act on the principal's behalf (Bergen et al. 1992). A core concern in agency constellations is to insure that the agent acts on behalf and in the best interest of the principal, as opposed to shirking such responsibility. Applied to an HRM context, responsibility for the management of human resources is typically delegated by the franchisor without much regulation to individual franchisees, despite the common assumption that in franchise systems, virtually every aspect is regulated via contract in order to ensure system-wide standardization (Grünhagen et al. 2013). There may be variation between franchise systems as regards the level of franchisee HR autonomy (Grünhagen et al. 2013); however, several studies have found that franchisees generally have quite significant HR autonomy in their units ${ }^{1}$ (Brand and Croonen 2010; Burgers et al. 2010; Mumdžiev and Windsperger 2011; Truss 2004; Windsperger 2004). The major reasons for this franchisee HR autonomy are to maintain franchisee satisfaction and motivation (Truss

\footnotetext{
${ }^{1}$ Some studies have found that employee training may be an exception to this (e.g. Burgers et al. 2010; Truss 2004).
} 
2004), and to avoid legal risks for the franchisor (Brand and Croonen 2010). Yet, despite the franchisees' autonomy regarding HRM, not much is known about how franchisees utilize the relatively large degree of autonomy they receive, and the effectiveness of their HR practices, resulting in a recent call for more studies of HRM and its impact on performance at the franchise unit level (Grünhagen et al. 2013).

While research has investigated and compared single-unit franchisees (i.e. franchisees operating one single unit; SUFs) to company-owned units (COs) in terms of HR intensity and HR performance (Brand and Croonen 2010), little is known about multiunit franchisees (i.e. franchisees that operate more than one unit within a franchise system; MUFs) and their HR practices. This reflects a general tendency of the franchising literature to focus on SUFs (Dant et al. 2013). This relative lack of research on MUFs is surprising given the fact that MUF has now been recognized as a pervasive and dominant form of franchising in a range of industries and countries (e.g. Grünhagen and Mittelstaedt 2005; Hussain et al. 2013; Weaven and Frazer 2006). Additionally, MUFs possess unique characteristics in that they contradict accepted explanations for franchising through the separation of unit ownership and unit control (Garg et al. 2013; Jindal 2011). The studies that have dealt with MUFs have mostly focused on explaining the use of MUF by franchisors (e.g. Jindal 2011; Kalnins and Lafontaine 2004; Kaufmann and Dant 1996) or franchisees (e.g. Dant et al. 2013; Grünhagen and Mittelstaedt 2005). However, very little is known about the actual behaviors of MUFs in running their units and the consequences for performance at the unit level.

Given this knowledge gap, the importance of HRM for franchise systems, the increasing popularity of MUF and the unique characteristics of MUFs, our study's contribution to the franchising literature is to develop propositions on how units with different ownership structures (i.e. COs, SUFs and MUFs) deal with HRM and how this affects unit performance. In doing so, we start with a brief review of the current literature on HRM and performance in different contexts, including the franchising context. Second, we build on an integrative review of resource, entrepreneurship and agency perspectives to discuss the unique characteristics of unit ownership type in relation to the adoption of HRM approaches at the unit level. We then discuss our propositions on how these unit level HR practices affect unit HR performance. We conclude this conceptual paper with recommendations for future research and implications for franchise practice.

\section{Theoretical backgrounds and propositions}

\section{HRM and performance (in franchising)}

HRM refers to a set of policies and practices directed at attracting, developing and maintaining a firm's human resources (Lado and Wilson 1994), and it generally includes policies and practices in the following domains: job analysis and design, recruitment and selection, training and development, performance management, pay structures and incentives and benefits, and labor and employee relations (e.g. Noe et al. 2003). 
Numerous studies have attempted to empirically study the link between HRM and firm performance $^{2}$ in different contexts (e.g. Arthur 1994; Bowen and Ostroff 2004; Kidwell and Fish 2007). There are three dominant theoretical perspectives focusing on the relationship between HRM and performance (Delery and Doty 1996; Lepak and Shaw 2008; Samnani and Singh 2013). The first perspective is the universalistic theory, which suggests that certain key HR practices will lead to firm performance regardless of the organizational context (Danvilla del Valle and Sastre Castillo 2009). This theoretical stream thus assumes that the positive impact on performance of some HR practices is so well documented in multiple contexts that managers can adopt these 'best practices' in their own firms in order to maintain or increase performance (Grünhagen et al. 2013). A second group of researchers has adopted a contingency perspective by arguing that an organization's HR practices must be consistent with the characteristics of the organization, such as strategy (Delery and Doty 1996) and/or the environment (Samnani and Singh 2013). Researchers in this theoretical stream assume that firms need to select 'best fit' HR practices that fit with the context in which they operate in order to be maximally effective. A third group of researchers has adopted a configurational perspective and have tried to identify combinations or aligned 'bundles' of HR practices that yield superior outcomes (e.g. Arthur 1994; Huselid 1995). Several researchers refer to these configurations as 'systems' of HR practices, and they have distinguished a variety of HR systems, such as 'systems of control' and 'systems of commitment' (Arthur 1994, and see Lepak and Shaw 2008 and Lepak et al. 2006 for more examples). This configurational perspective assumes that organizations may adopt different systems on the basis of their own organizational objectives, for example: some organizations may be more focused on controlling employees, whereas others may consider creating and maintaining commitment among the employees as more important. The configurational perspective is relatively new, and several key questions regarding the conceptualization of HRM systems still remain (Lepak and Shaw 2008).

In this study, we follow a configurational approach by proposing that managers/ franchisees of units will adopt systems of HR practices in their units that will ultimately affect unit HR performance. We distinguish between two types of HRM systems that can be implemented in units (cf. Grünhagen et al. 2013). The first one is the 'best fit' system where the units use bundles of HR practices that are adapted to their local environments and the unit employees. These practices may be formalized, but they are very likely to include informal HR practices, such as paying attention to employee birthdays and anniversaries (cf. Brand and Croonen 2010) so as to reinforce and personalize the owner's ability to relate to employees and their needs. The second system type is the 'best practice' system where units implement bundles of HR practices that have proven to work in other contexts and that are to a large extent standardized and formalized. Examples of best practices include procedures for selection and training of new employees according to a checklist, routinized manual or prescribed orientation that can be repeated throughout the units. The best practice approach is often justified by arguing that consistency brings efficiency to the

\footnotetext{
$\overline{2}$ The relationship between HRM and firm performance is a very complex one, and researchers have pointed at various variables that mediate the relationship between HR practices and firm performance. Sels et al. (2006) distinguish three hierarchical levels of performance with the first level being employee behavioral outcomes, the second level being employee performance outcomes and the third and ultimate level being firm performance. The first level affects the second level, which ultimately affects the third level.
} 
organization (Jennings et al. 2009). Units can derive these best practices from different sources. Within franchise systems, the franchisor can be an important-and relatively cheap - source of such practices given that the franchisor has accumulated experiences regarding HRM at the unit level. Second, best practices can also be transferred by external (HRM) consultants with accumulated experiences regarding HRM in different contexts. Finally, franchisees can build on their own experiences to develop formal best practices; however, below we will propose that only franchisees with a large number of units will do this.

Even though there are numerous studies on HRM and performance in a range of organizational contexts, very few studies have empirically investigated how franchisors and franchisees apply HRM (exceptions are Krueger 1990; Litz and Stewart 2000; Felstead 1993 and Truss 2004), and, to our knowledge, studies linking HRM to performance in a franchise context are even more rare (two exceptions are Brand and Croonen 2010 and Grünhagen et al. 2013). The study of franchisee HRM behaviors and their impact on performance is important since franchisees generally have a large degree of freedom in adopting HR practices in their units. An important question, thus, is how franchisees use their discretion regarding HRM and how this affects performance.

The study by Grünhagen et al. (2013) showed that system performance is positively enhanced through the freedom a franchisor offers to franchisees throughout a system with regards to their creation of HR practices, i.e. 'HR Operational Autonomy'. While the research was conducted at the system level, Grünhagen et al. (2013) recognized this limitation and called for the study of HR practices and their impact on unit level performance. One of the few HRM studies at the unit level is the empirical study of Brand and Croonen (2010) on HR practices and unit performance within one large Dutch franchise system. Their study showed that even though franchised units have a relatively low HRM intensity compared to company-owned units, the franchised units - and especially the smaller ones - had superior unit HR performance. HRM intensity ${ }^{3}$ was defined as the extent of use of a set of HR practices that cover the abovementioned major HR domains of job analysis and design, recruitment and selection, training and development, performance management, pay structures and incentives and benefits, and labor and employee relations.

The abovementioned studies of Brand and Croonen (2010) and Grünhagen et al. (2013) have not explicitly included MUFs, whereas the unique characteristics of MUFs may lead to specific characteristics of their HRM systems (i.e. configurations of internally aligned HR practices) that ultimately affect unit HR performance. As we will argue below on the basis of resource, entrepreneurship and agency perspectives, COs, SUFs and MUFs have different characteristics, and they are therefore likely to differ in their HRM systems, which ultimately affects their units' HR performance.

\section{Types of unit ownership and their consequences for HRM systems}

The differences in governance and management of franchised and company-owned units have been discussed and studied extensively (e.g. Bürkle and Posselt 2008; Castrogiovanni

\footnotetext{
${ }^{3}$ Another well-known concept is HR formalization (e.g. Kotey and Slade 2005); however, HRM intensity is a broader concept that includes HRM practices that are formalized (e.g. use of job descriptions), and HRM practices that are not formalized (e.g. the use of nonmonetary rewards).
} 
and Kidwell 2010; Yin and Zajac 2004). The same applies to the differences between SUFs and MUFs (e.g. Grünhagen and Mittelstaedt 2005; Jindal 2011; Weaven and Frazer 2006). Integrating entrepreneurial, agency and resource perspectives, the differences between these ownership types can be described along four dimensions (Brand and Croonen 2010; Grünhagen et al. 2013; Jindal 2011; Yin and Zajac 2004; Sorenson and Sørensen 2001): the level of operational autonomy regarding HRM, incentives for local adaptation, monitoring and control systems, and the availability of resources and economies of scale. We propose that these differences also lead to differences in HRM systems adopted at each unit type and ultimately in unit HR performance.

The situation regarding HRM in MUFs compared to SUFs is complex since MUFs can take different forms, and 'MUF chains' (i.e. the collection of units owned by one franchisee) can differ in size, varying from just two, three or four units to several hundreds of units. To decrease complexity, we distinguish between 'small MUFs' (i.e. franchisees with only two or three units), medium-size MUFs (i.e. franchisees with four or five units), 'large' MUFs (i.e. franchisees with more than five units). ${ }^{4}$

\section{HRM systems in COs}

Company-owned units are owned by the headquarters and run by company managers who generally have very few decision rights in running the units (Bradach 1998; Yin and Zajac 2004). These low levels of decision rights also apply to HRM activities (Brand and Croonen 2010). In other words, company-owned units have a very low level of 'HR operational autonomy' (cf. Grünhagen et al. 2013). Additionally, due to the fact that company managers are employees of the headquarters, they have few incentives to engage in local adaptation and entrepreneurial initiatives (Bradach 1998; Sorenson and Sørensen 2001), and this includes local adaptation regarding HRM. Moreover, company managers are controlled and monitored to a great extent (Sorenson and Sørensen 2001; Yin and Zajac 2004). Thus, company managers likely follow the HR policies and practices that are developed and imposed by headquarters. Finally, from a resource perspective, headquarters generally have a large number of units and, thus, the resources and the incentives to develop formal and standardized HR practices (Brand and Croonen 2010). Given that headquarters generally have units that are geographically dispersed, we propose that headquarters develop formal and standardized HR practices that work in a range of contexts. In other words, headquarters will adopt a best practice HRM system that is implemented across all company-owned units.

\section{HRM systems in SUFs and small MUFs}

Since franchisees own the assets and are the residual claimants of their units, they generally enjoy a higher level of operational autonomy than company managers, for example regarding price levels, hours of service, and hiring (Michael 1996). As argued

\footnotetext{
${ }^{4}$ The exact number of units that would lead to 'typical' HRM behaviors of medium-size MUFs is somewhat arbitrary: this depends on different factors, such as the industry, geographical proximity between the units, and the number of employees in the units. Empirical studies will have to include such factors to define different types of MUFs. However, to provide an industry reference: Bennett (2008) cites FRANData President Darrell Johnson and delineates franchisees along the following lines: SUFs control half of all US franchised units, MUFs who operate two to five units own another fourth of all US units, and one-fourth are owned by franchisees with five or more units.
} 
in this paper's introduction, franchisees often have high levels of operational autonomy regarding HRM. Additionally, the headquarters' monitoring of franchisees is less stringent and systematic than the monitoring of company managers (Sorenson and Sørensen 2001; Yin and Zajac 2004), which provides franchisees with room to engage in their own HR practices. Moreover, due to their asset ownership and residual claimant status, franchisees are generally assumed to have many incentives to engage in entrepreneurial initiatives and local adaptation (Michael 2002; Sorenson and Sørensen 2001), including local adaptation regarding HRM (Brand and Croonen 2010). These incentives for local adaptation are very likely to lead to a SUF's adoption of a best fit system since such a system-which would typically include informal practices - enables the SUF to personalize its HR practices and to adapt to its own local needs. Moreover, due to their regular physical presence in the store SUFs may not want to formalize their HR practices because the small firm size enables them to have close and informal relationships with their employees and to personally supervise them (Brand and Croonen 2010; Kidwell and Fish 2007). Finally, with respect to resources and economies of scale, it can be argued that SUFs will run their units as typical small business owners. It is likely that they have relatively few resources and economies of scale that enable them to develop best practice HRM systems (Patel and Cardon 2010).

Given the above considerations, we thus propose that SUFs are likely to adopt a best fit HRM system. However, we have to refine this idea since franchisors may also present information to their franchisees regarding HRM best practices ${ }^{5}$. Franchisees may 'cherry-pick' from these franchisor best practices, which may result in a franchisee combining best fit and best practice HRM systems (cf. Grünhagen et al. 2013). The factors that may affect the degree of cherry-picking are outside the scope of this research, but a franchisee's personal characteristics, such as entrepreneurial experience or management style, may be relevant factors. Nevertheless, we assume that SUFs will always have a relatively high degree of best fit practices in their units since their physical presence in their units enables them to manage their employees in a personalized and informal manner that fits with their local circumstances.

Regarding the abovementioned dimensions, we do not expect many differences between SUFs and MUFs owning a very small number of units (i.e. only two or three units). Just as the SUFs, very small MUFs can still be physically present in each unit on a very regular basis, understand each unit's local environment and they can closely monitor the unit employees ${ }^{6}$. Both the SUFs and these small MUFs will have the

\footnotetext{
${ }^{5}$ Here we assume that franchisors will have information about HRM best practices. Franchisors of systems with company-owned units are very likely to have such information because this information is critical for managing their own company-owned units. However, franchisors of systems with solely franchised units may be less likely to have it. Future research should thus take into account the extent to which the franchisor provides information about HR best practices.

${ }^{6}$ We have to point at two additional and potentially relevant variables. First, MUFs can also have business partners or family members amongst whom tasks can be divided. For example, in the case of a small MUF chain, one person can run unit 1 and the other can run unit 2. This may affect the level of local adaptation of HR practices. Second, the geographical distance among units within MUF chains can differ (and this may also be contingent on the type of industry in which the MUF operates). We expect that in most cases MUFs will own units that are geographically close to each other, but in some cases the distance between the units may be quite large. This distance can affect the HRM system that is adopted, and ultimately, unit performance. For the sake of simplicity, we have left these variables out of the theoretical discussion. However, they would have to be controlled for in an empirical study.
} 
incentives to adopt a best fit HRM approach by developing HRM practices that fit with their local contexts. Additionally, we expect a relatively large informal component since these franchisees do not have the resources and economies of scale to develop more formal HRM practices.

\section{HRM in medium-size and larger MUFs}

Just as is the case for SUFs, franchisors are likely to grant MUFs a high level of HR operational autonomy regarding their units. However, from an agency perspective, MUFs differ from SUFs in the sense that the risks of shirking at the unit level are reintroduced. MUFs generally delegate operational autonomy for running the units to managers, and, as a result, the agency problems that are generally 'solved' through franchising are reintroduced through MUF (Jindal 2011; Garg et al. 2013). Especially the larger MUFs cannot operate all their units by themselves and need to hire managers to run the units. These managers, like managers of company-owned units, generally receive a fixed salary, incentives to shirk and, thus, need to be monitored (Combs and Ketchen 2003). As a result, we can expect that large MUFs will adopt best practice HRM systems with formal and standardized procedures that work in a range of contexts and that will be implemented in all their units. As we argued earlier, these best practices may have been provided to the MUF by the franchisor or a consultant, or the MUF may have built on its own accumulated experience to develop best practices. In case the franchisor does not provide best practices, the larger MUFs will have the resources and the scale economies to have such practices developed (cf. Jennings et al. 2009).

For the medium-size MUFs the situation is somewhat more complicated. These MUFs will have more difficulties in developing a best fit HRM system because the number of units is just too large for the franchisee (and its business partners) to be physically present at each unit on a very regular basis and thus to personally manage and monitor the employees. We therefore propose two possible options for these mediumsize MUFs. First, in case their franchisor has best practices (see footnote 5), it is very likely that these medium-size MUFs will largely adopt these practices since this is a relatively cheap way of obtaining best practices. Second, in case their franchisor does not provide best practices, the medium-size MUFs run the risk of becoming 'stuck in the middle' or 'schizoid' regarding their HR system (cf. Jennings et al. 2009). These MUFs may decide to develop their own best practice system (with or without the help of a consultant), but this incurs high development costs in terms of time and money (De Kok et al. 2006; Jennings et al. 2009). These costs may be problematic for the medium-size MUFs since - just as many other small- and medium-size enterprises or SMEs - they are likely to suffer from resource limitations and lack of economies of scale (De Kok et al. 2006; Jennings et al. 2009). The resource limitations (e.g. in terms of financial resources and managerial resources) may prevent the medium-size MUF from spending time and money on developing valid best practices.

Table 1 summarizes the relative differences between unit types and their HRM systems.

\section{Propositions on unit ownership and HR performance}

An important question is how the use of different HRM systems (i.e. best fit or best practice) affects performance at the unit level. Researchers adopting a configurational 
Table 1 Relative differences between unit types

\begin{tabular}{|c|c|c|c|c|c|}
\hline $\begin{array}{l}\text { Unit } \rightarrow \\
\text { characteristics } \\
\text { Unit type } \downarrow\end{array}$ & $\begin{array}{l}\text { Unit HR } \\
\text { operational } \\
\text { autonomy }\end{array}$ & $\begin{array}{l}\text { Incentives } \\
\text { for HR local } \\
\text { adaptation } \\
\text { at unit level }\end{array}$ & $\begin{array}{l}\text { Degree of } \\
\text { control and } \\
\text { monitoring on } \\
\text { HR activities } \\
\text { at the unit level }\end{array}$ & $\begin{array}{l}\text { Resource } \\
\text { availability } \\
\text { and economies } \\
\text { of scale }\end{array}$ & $\begin{array}{l}\text { Resulting } \\
\text { unit HRM } \\
\text { system }\end{array}$ \\
\hline Company-owned unit & Low & Low & High & High & 'Best practice' \\
\hline $\begin{array}{l}\text { Unit owned by } \\
\text { SUF/'small' } \\
\text { MUF }\end{array}$ & High & High & High & Low & 'Best fit' \\
\hline $\begin{array}{l}\text { Unit owned by a } \\
\text { 'medium-size' } \\
\text { MUF }\end{array}$ & Medium & Medium & Low & Medium & $\begin{array}{l}\text { 'Best practice' } \\
\text { or 'Stuck } \\
\text { in the middle'. }\end{array}$ \\
\hline $\begin{array}{l}\text { Unit owned by } \\
\text { a 'large' MUF }\end{array}$ & Low & Low & High & High & 'Best practice' \\
\hline
\end{tabular}

perspective have argued that different systems of HR practices can be equally effective (e.g. Becker and Huselid 2010; Delery and Doty 1996). A major disadvantage of a best practice HRM system is that it may result in standardized HR practices that are suboptimal at the unit level (Becker and Huselid 2010; Samnani and Singh 2013). On the other hand, these best practices are transferable across organizations and units and, thus, require little trial and error and distractions at the unit level (Samnani and Singh 2013). Moreover, by means of using best practices a unit may acquire a comprehensible and legitimate identity (Jennings et al. 2009). A best fit system, by definition, has a closer fit with the local environment; however, it may take quite some trial and error to figure out which practices may work and which may not (Jennings et al. 2009). These considerations lead to the following contrasting propositions:

Proposition 1: Units owned by SUFs and small MUFs will have higher unit HR performance than units owned by large MUFs because of their use of best fit HRM systems.

Proposition 2: Units owned by large MUFs will have higher unit HR performance than units owned by SUFs and small MUFs because of their use of best practice HRM systems.

As pointed out, some medium-size MUFs may be 'stuck in the middle' regarding their HR practices. The result may be an unaligned mix of HR practices that leads to confusion among employees and a lower HR performance compared to the best practice and best fit systems that are relatively aligned (cf. Subramony 2009; Jennings et al. 2009). Hence:

Proposition 3: Units owned by medium-size MUFs have the lowest unit HR performance due to being stuck in the middle in terms of HRM systems.

The above propositions are summarized in Fig. 1. Figure 1 presents the relationship between the number of units owned by a franchisee and unit HR performance. The 


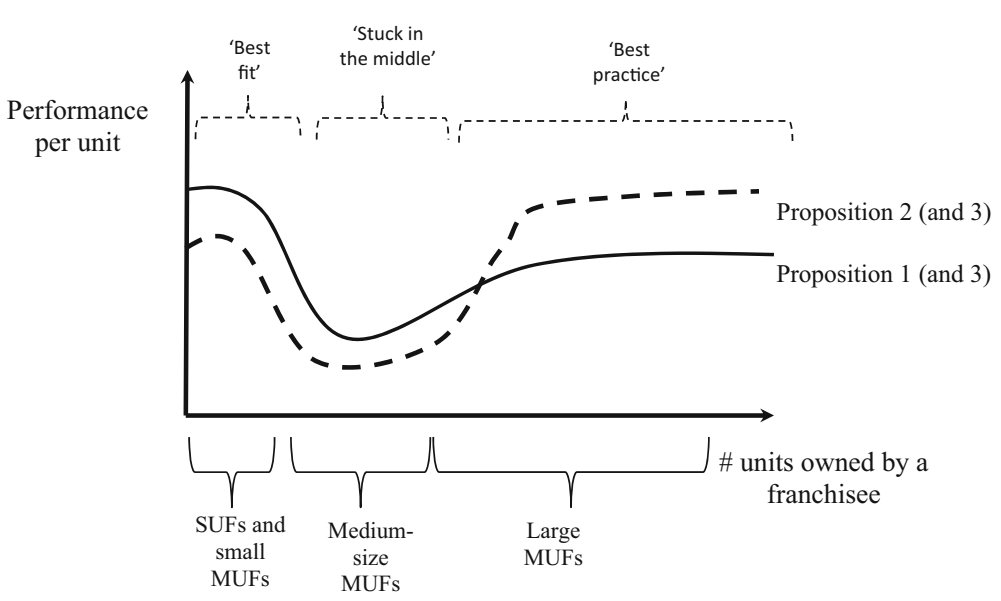

Fig. 1 Proposed relationships between the number of units owned by a franchisee and unit performance

solid line represents the situation according to Propositions 1 and 3; the dashed line represents Propositions 2 and 3. As pointed out, propositions 1 and 2 are contrasting propositions, and therefore Fig. 1 presents two different patterns.

Finally, regarding company-owned units (COs), we expect that unit performance in systems with a small number of COs is initially low because these units may have the same issues as medium-size MUFs and they may be stuck in the middle regarding their HRM systems. However, we expect that headquarters are quickly able to build best practices regarding HRM for their units. Following Winter and Szulanski (2001), we assume that headquarters learn about the best HR practices for their units as the system grows; in other words, the best practices are optimized when the number of companyowned units becomes larger. The larger the number of COs in the system, the higher $\mathrm{CO}$ unit HR performance (although this levels off at a certain point). This results in the following proposition:

Proposition 4: The higher the number of units owned by a single party (i.e. COs owned by headquarters or units owned by a large MUF), the more best practices are used and the higher unit HR performance.

\section{Contributions and implications}

Multi-unit franchisees represent a very unique structural arrangement in the franchise realm, as these entrepreneurs operate essentially a mini-chain of units under the 'umbrella' of a franchise arrangement (Grünhagen and Mittelstaedt 2005). As such, this very unique organizational structure creates its own challenges as outlined in the literature (e.g. Jindal 2011). While the literature to date has examined the performance implications of HRM at the franchise system level (Grünhagen et al. 2013) as well as at the franchised unit level (Brand and Croonen 2010), this study represents the first attempt to conceptualize the HRM-performance link for a more complex entrepreneurial structure where ownership and management are separated, i.e. in the context of MUFs and their units. 
This paper establishes a set of propositions that build on agency, resource and entrepreneurship perspectives, contrasting the HRM-performance link between the typical unit-ownership arrangements in franchised firms, i.e. SUFs, MUFs and COs. We propose that units owned by SUFs and by smaller MUFs adopt a best fit HRM system, whereas COs and units owned by larger MUFs typically adopt a best practice HRM system. For medium-size MUFs the situation is somewhat more complicated: they may either adopt a best practice system or they may become stuck in the middle. Finally, we propose that each HRM system has its own advantages and disadvantages, which results in contrasting propositions regarding their effects on unit HR performance.

If, in fact, the empirical test of these propositions holds up, significant implications for practitioners can be envisioned. While a locally-adapted best fit system for SUFs and a more standardized best practice system for COs continue to make sense for these respective ownership arrangements, MUFs may have to consider their individual situations, and attempt to find the appropriate approach for themselves, in coordination with the franchisor, in order to avoid getting stuck in the middle. Given that MUFs with a relatively small set of units are quite common (e.g. McDonald's average franchisee owns five units, see Loten 2012), this study provides an important differentiated contribution to the management of this very typical ownership arrangement.

Regarding the actual empirical testing of the propositions developed in this paper, several issues have to be taken into account. First, the conceptualization of the different HRM systems is a challenging task. Although there is agreement in the HRM literature that bundles or systems of HR practices exist, there is much less agreement on the conceptualization and operationalization of such systems (Arthur 1994; Lepak et al. 2006; Lepak and Shaw 2008). The first step is, thus, to develop more refined conceptualizations of best fit and best practice HRM systems in franchise systems as a specific entrepreneurial context.

Second, for the sake of readability and understandability, this paper has presented a rather straightforward conceptual framework. However, there are several important contextual variables that have to be controlled for in an empirical study in order to enhance internal validity (cf. Davies et al. 2011). Some of these variables can be controlled by means of selecting specific countries, industries and types of franchise systems. Regarding country selection, the first empirical investigation ought to focus on one country to control for differences in institutional environments (e.g. legislation regarding HRM) that may affect the adoption of HRM systems (Thach and Kidwell 2009). Moreover, multi-unit ownership has been a trend for the past couple of decades in the US market (Kaufmann and Dant 1996); however, the MUF phenomenon is at a much less mature stage in many other countries. For example, MUFs have only recently become more popular in countries such as Australia (Weaven and Frazer 2006) or the Netherlands (ING Economisch Bureau 2012). Regarding industry selection, we also advise to select one specific industry for the first empirical test since industries can differ on important contextual variables as well. Important examples of such variables are: the typical geographical distance between units and the typical number of employees in a unit. Building on an agency perspective (Combs and Ketchen 2003), geographical dispersion of units increases a small MUF's costs of personally supervising and monitoring the unit employees, which makes the adoption of a best fit HRM system less attractive and feasible. The geographical distance 
between units can be relatively small, for example in fast food or convenience stores. Additionally, the typical number of employees in a unit may affect the adoption of HRM systems as well; if the number of employees is generally low a best fit system may be attractive and feasible; however, a best practice system may be needed when the number of unit employees is high. Regarding franchise system selection, important contextual variables are the system's share of company-owned units, the size of the franchise system in terms of number of units, and the franchise system's strategy. As pointed out earlier, the presence of company-owned units and a large system size are likely to increase the availability of best practices at the franchisor. Moreover, several researchers have argued that HR practices should also be aligned with firm strategy (e.g. Delery and Doty 1996; Lepak and Shaw 2008); a franchisor that aims for a high level of standardization may be to some extent inclined to impose best practices on their franchisees. Even though several studies have found that franchisees generally have quite some HR autonomy (see the Introduction), we advise researchers to carefully select franchise systems with ample franchisee HR autonomy to empirically test our theoretical framework.

Third, once researchers have selected the country, industry and franchise system(s), we advise to do some exploratory interviews with franchisor representatives, SUFs, MUFs and company managers to gain an insight into the research context, to become aware of additional control variables and to develop survey measures. The survey has to contain questions regarding the unit level and has to be filled out by the person that is responsible for the daily management of the unit. This is important because there may be differences between the formal and actual situation at the unit level (e.g. especially large MUFs may not know what is really going on regarding staff in their individual units). Regarding HR-performance, we already pointed out that this can be measured at different hierarchical levels (see footnote 1). An additional consideration is to look at the possibilities of acquiring HR-performance data from another source in order to prevent common method bias (Podsakoff et al. 2003); for example, researchers may use HR-performance data from the franchisor's benchmarking system (if available). Another, and more challenging, option would be to collect data on HR performance (e.g. employee satisfaction) at the employee level.

A final issue regarding empirical testing is that this study has not taken into account the ever-growing number of franchisees with ownership of units across different systems, so-called 'portfolio franchisees'. Clearly, such cross-system multi-unit ownership structures may provide additional opportunities from an HRM standpoint, for example the movement or promotion of employees from a unit in one system to one in a different system, all owned by the same portfolio MUF. Incorporating portfolio franchisees into future research on this topic is strongly recommended due to the myriad additional HRM perspectives such arrangements open up for franchisees.

Open Access This article is distributed under the terms of the Creative Commons Attribution 4.0 International License (http://creativecommons.org/licenses/by/4.0/), which permits unrestricted use, distribution, and reproduction in any medium, provided you give appropriate credit to the original author(s) and the source, provide a link to the Creative Commons license, and indicate if changes were made. 


\section{References}

ADP (2013). ADP National Franchise Report for November 2013. Roseland NJ: ADP Research Institute. http://www.adp.com/media/press-releases/2013-press-releases. Accessed 19 Dec 2013.

Arthur, J. B. (1994). Effects of human resource systems on manufacturing performance and turnover. Academy of Management Journal, 37(3), 670-687.

Becker, B. E., \& Huselid, M. A. (2010). SHRM and job design: narrowing the divide. Journal of Organizational Behavior, 31(2-3), 379-388.

Bennett, J. (2008). Multi-unit franchising trend taking over industry. Industry Business Journal. http://www. indusbusinessjournal.com/ME2/Audiences/dirmod.asp. Accessed 4 September 2013.

Bergen, M., Dutta, S., \& Walker, O. C., Jr. (1992). Agency relationships in marketing: a review of the implications and applications of agency and related theories. Journal of Marketing, 56(July), 1-24.

Bowen, D. E., \& Ostroff, C. (2004). Understanding HRM-firm performance linkages: the role of the 'strength' of the HRM system. Academy of Management Review, 29(2), 203-221.

Bradach, J. L. (1998). Franchise organizations. Harvard Business Review Press.

Brand, M. J., \& Croonen, E. P. M. (2010). Franchised and small, the most beautiful of all: HRM and performance in plural systems. Journal of Small Business Management, 48(4), 605-626.

Burgers, J. A. I. M., Croonen, E. P. M., \& Brand, M. J. (2010). De hardheid van Nederlandse franchiseformules. In Franchise; soft of hard. Hilversum: Nederlandse Franchise Vereniging (NFV).

Bürkle, T., \& Posselt, T. (2008). Franchising as a plural system: a risk-based explanation. Journal of Retailing, $84,39-47$.

Castrogiovanni, G. J., \& Kidwell, R. E. (2010). Human resource management practices affecting unit managers in franchise networks. Human Resource Management, 49(2), 225-239.

Combs, J. G., \& Ketchen, D. J. (2003). Why do firms use Franchising as an entrepreneurial strategy?: A metaanalysis. Journal of Management, 29(3), 443-465.

Dant, R. P., Weaven, S., Baker, B., \& Jean, H. (2013). Erratum to: an introspective examination of single-unit versus multi-unit franchisees. Journal of the Academy of Marketing Science, 41(4), 497-500.

Danvilla del Valle, I., \& Sastre Castillo, M. A. (2009). Human capital and sustainable competitive advantage: an analysis of the relationship between training and performance. International Entrepreneurship and Management Journal, 5, 139-163.

Davies, M. A. P., Lassar, W., Manolis, C., Prince, M., \& Winsor, R. D. (2011). A model of trust and compliance in franchise relationships. Journal of Business Venturing, 26, 321-340.

De Kok, J. M. P., Uhlaner, L. M., \& Thurik, A. R. (2006). Profesional HRM practices in family ownedmanaged enterprises. Journal of Small Business Management, 44(3), 441-460.

Delery, J. E., \& Doty, D. H. (1996). Modes of theorizing in strategic human resource management: tests of universalistic, contingency, and configurational performance predictions. Academy of Management Journal, 39(4), 802-835.

Felstead, A. (1993). The corporate paradox: Power and control in the business franchise. Routledge.

Garg, V. K., Priem, R. L., \& Rasheed, A. A. (2013). A theoretical explanation of the cost advantages of multiunit franchising. Journal of Marketing Channels, 20(1-2), 52-72.

Gillis, W., \& Castrogiovanni, G. J. (2012). The franchising business model: an entrepreneurial growth alternative. International Entrepreneurship and Management Journal, 8, 75-98.

Grünhagen, M., \& Mittelstaedt, R. A. (2005). Entrepreneurs or investors: do multi-unit franchisees have different philosophical orientations? Journal of Small Business Management, 43(3), 207-225.

Grünhagen, M., Wollan, M. L., Dada, L. O., \& Watson, A. E. (2013). The moderating role of HR operational autonomy on the entrepreneurial orientation-performance link in franchise systems. International Entrepreneurship and Management Journal. doi:10.1007/s11365-013-0270-7.

Huselid, M. A. (1995). The impact of human resource management practices on turnover, productivity, and corporate financial performance. Academy of Management Journal, 38(3), 635-672.

Hussain, D., Perrigot, R., Mignonac, K., El Akremi, A., \& Herrbach, O. (2013). Determinants of multi-unit franchising: an organizational economics framework. Managerial and Decision Economics, 34(3-5), 161-169.

ING Economisch Bureau (2012). Multifranchise wint aan belang. ING Economisch Bureau, December 2012.

Jennings, J. E., Jennings, P. D., \& Greenwood, R. (2009). Novelty and new firm performance; the case of employment systems in knowledge-intensive service organizations. Journal of Business Venturing, 24, 338-359. 
Jindal, R. (2011). Reducing the size of internal hierarchy: the case of multi-unit franchising. Journal of Retailing, 87(4), 549-562.

Kalnins, A., \& Lafontaine, F. (2004). Multi-unit ownership in franchising: evidence from the fast-food industry in Texas. The RAND Journal of Economics, 35(4), 747-761.

Kaufmann, P. J., \& Dant, R. P. (1996). Multi-unit franchising: growth and management issues. Journal of Business Venturing, 11(5), 343-358.

Ketchen, D. J., Short, J. C., \& Combs, J. G. (2011). Is franchising entrepreneurship? Yes, no, and maybe so. Entrepreneurship: Theory and Practice, 35(3), 583-593.

Kidwell, R. A., \& Fish, A. J. (2007). High-performance human resource practices in Australian family businesses: preliminary evidence from the wine industry. International Entrepreneurship and Management Journal, 3, 1-14.

Kotey, B., \& Slade, P. (2005). Formal human resource management practices in small growing firms. Journal of Small Business Management, 43(1), 16-40.

Krueger, A. B. (1990). Incentive effects of workers' compensation insurance. Journal of Public Economics, 41, 73-99.

Lado, A. A., \& Wilson, M. C. (1994). Human resource systems and sustained competitive advantage: a competency-based perspective. Academy of Management Review, 19(4), 699-727.

Lepak, D. P., \& Shaw, J. D. (2008). Strategic HRM in North America: looking to the future. International Journal of Human Resource Management, 19(8), 1486-1499.

Lepak, D. P., Liao, H., Chung, Y., \& Harden, E. E. (2006). A conceptual review of human resource management systems in strategic human resource management research. Research in Personnel and Human Resources Management, 25, 217-271.

Litz, R. A., \& Stewart, A. C. (2000). Research note: trade name franchise membership as a human resource management strategy: does buying group training deliver 'true value' for retailers? Entrepreneurship Theory \& Practice, 25(1), 125-135.

Loten, A. (2012). The big get bigger. The Wall Street Journal. http://online.wsj.com/article/ SB10001424052702304723304577370431589231276.htm. Accessed 4 Sept 2013.

McLean, M. (2006). Evaluating the importance and performance of the human resources function: an examination of a medium sized Scottish retailer. Journal of Retailing and Consumer Services, 13(2), $143-156$.

Michael, S. C. (1996). To franchise or not to franchise: an analysis of decision rights and organizational form shares. Journal of Business Venturing, 11, 57-71.

Michael, S. C. (2002). Can a franchise chain coordinate? Journal of Business Venturing, 17(4), 325-341.

Miller, D. (2006). Strategic human resource management in department stores: an historical perspective. Journal of Retailing and Consumer Services, 13(2), 99-109.

Mumdžiev, N., \& Windsperger, J. (2011). The structure of decision rights in franchising networks: a property rights perspective. Entrepreneurship: Theory and Practice, 35(3), 449-465.

Noe, R. A., Hollenbeck, J. R., Gerhart, B., \& Wright, P. (2003). Human resource management: Gaining a competitive advantage. New York: McGraw-Hill/Irwin.

Patel, P. C., \& Cardon, M. S. (2010). Adopting HRM practices and their effectiveness in small firms facing product-market competition. Human Resource Management, 49(2), 265-290.

Podsakoff, P. M., MacKenzie, S. B., Lee, J. Y., \& Podsakoff, N. P. (2003). Common method biases in behavioral research; a critical review of the literature and recommended remedies. Journal of Applied Psychology, 88(5), 879-903.

Samnani, A., \& Singh, P. (2013). Exploring the fit perspective: an ethnographic approach. Human Resource Management, 52(1), 123-144.

Sels, L., De Winne, S., Delmotte, J., Maes, J., Faems, D., \& Forrier, A. (2006). Linking HRM and small business performance; an examination of the impact of HRM intensity on the productivity and financial performance of small businesses. Small Business Economics, 26, 83-101.

Sorenson, O., \& Sørensen, J. B. (2001). Finding the right mix: franchising, organizational learning, and chain performance. Strategic Management Journal, 22(6-7), 713-724.

Subramony, M. (2009). A meta-analytic investigation of the relationship between HRM bundles and firm performance. Human Resource Management, 48(5), 745-768.

Thach, L., \& Kidwell, R. E. (2009). HR practices in US and Australian family wineries: cultural contrasts and performance impact. International Entrepreneurship and Management Journal, 5, 219-240.

Truss, C. (2004). Who's in the driving seat? Managing human resources in a franchise firm. Human Resource Management Journal, 14(4), 57-75.

Weaven, S., \& Frazer, L. (2006). Investment incentives for single and multiple unit franchisees. Qualitative Market Research: An International Journal, 9(3), 225-242. 
Welsh, D. H. B., Alon, I., \& Falbe, C. M. (2006). An examination of international retail franchising in emerging markets. Journal of Small Business Management, 44, 130-149.

Windsperger, J. (2004). Centralization of franchising networks: evidence from the Austrian franchise sector. Journal of Business Research, 57(12), 1361-1369.

Winter, S. G., \& Szulanski, G. (2001). Replication as strategy. Organization Science, 12(6), 730-743.

Yin, X., \& Zajac, E. J. (2004). The strategy/governance structure fit relationship: theory and evidence in franchising arrangements. Strategic Management Journal, 25(4), 365-383. 